\title{
Precocious puberty in girls adopted from developing countries
}

\author{
Raffaele Virdis, Maria E Street, Maria Zampolli, Giorgio Radetti, Barbara Pezzini, \\ Marzia Benelli, Lucia Ghizzoni, Cecilia Volta
}

\begin{abstract}
Nineteen girls adopted from developing countries were referred for signs of idiopathic precocious puberty. After adoption, the catch up in linear and weight growth, together with improved nutritional and psychological conditions, may trigger the onset of puberty. Precocious puberty is a frequent and unnatural event in these girls. Treatment with gonadotrophin releasing analogues is indicated in patients diagnosed early, and when height prediction is poor.

(Arch Dis Child 1998;78:152-154)
\end{abstract}

Keywords: precocious puberty; developing countries; adoption; gonadotrophin releasing hormone analogues

Children adopted from developing countries may arrive at their new homes in a chronically undernourished state, with deficiency of both weight and height. They show rapid catch up growth and within a few months have reached their genetic target range of body size. ${ }^{1}$

Adopted Indian girls in Sweden are reported to have a significantly lower menarcheal age than either the indigenous population or their upper class Indian peers growing up in India. ${ }^{2}$ We also have observed increased referrals of such children for precocious puberty; these have all been females, and were mostly adopted from India into Italian families.

Department of
Paediatrics, University
of Parma, Italy
R Virdis
M E Street
M Zampolli
M Benelli
L Ghizzoni
C Volta

Department of Paediatrics, Regional Hospital, Bolzano, Italy

G Radetti

Department of Gynaecology, St Chiara Hospital, Trento, Italy B Pezzini

Correspondence to: Dr R Virdis, Istituto Policattedra di Pediatria, Via Gramsci 14, 43100 Parma, Italy.

Accepted 14 October 1997

\section{Methods}

Nineteen adopted girls were referred because of signs of precocious pubertal development. All came from developing countries, 15 from India. They arrived in Italy at a mean (SD) age of 4.0 (2.2) years (range 0.33 to 8 years) with evidence of chronic undernutrition. At the first visit, adoptive parents provided data about the country of origin, past medical history, and the habits and conditions of life before and after adoption. Consequently the first signs of puberty were accurately dated.

Height (Harpenden stadiometer), weight, skeletal maturation, ${ }^{3}$ pubertal development (Tanner stages), and height prediction ${ }^{45}$ were assessed at the first visit and on subsequent visits.

To compare growth data independently of age, we expressed height as height standard deviation score for age, and weight as the percentage of ideal weight for height (Tanner standards).

All the girls underwent hormonal investigations (gonadotrophin releasing hormone test, basal oestradiol, and androgens) and radiologi- cal imaging (cerebral computed tomography or magnetic resonance imaging and pelvic ultrasonography). Mean (SD) serum luteinising hormone after stimulation was 30.2 (20.2) IU/1 (in our laboratory, a value $>5 \mathrm{IU} / 1$ suggests the onset of puberty). No neurological abnormality was found on radiological imaging. Sixteen subjects were diagnosed as having idiopathic precocious puberty, and three as having early puberty.

The girls were divided into two groups. Group 1 consisted of 10 girls adopted before they were 4 years old and group 2 of nine girls adopted after they were 5. Group 2 started puberty within a few months of arrival (table 1).

Twelve of the 19 girls were treated with a gonadotrophin releasing hormone analogue (leuprorelin 3.75 or $7.5 \mathrm{mg}$ intramuscularly as a depot preparation every 28 days; seven in group 1 started treatment at a mean age of 8.2 (0.9) years and five in group 2 started at 7.5 (1.1) years).

Six months after beginning treatment a gonadotrophin releasing hormone test was carried out in all these patients to show adequate gonadotrophin suppression. This was confirmed: after stimulation, follicle stimulating hormone was 2.01 (1.32) IU/1, and luteinising hormone, 2.01 (1.89) IU/l. Bone age was also evaluated at regular intervals (every six to 12 months).

Seven patients were not treated because of late referral or a good initial predicted height.
STATISTICS

Values are reported as mean (SD). Student's $t$ test and one way analysis of variance were used to determine statistical significance; $\mathrm{p}<0.05$ was considered significant.

\section{Results}

At adoption, mean height SD score of all the girls was $-0.8(0.91)$ and weight deficit was $-10.9(9.6) \%$. Breast development began at 6.9 (1.0) years. At the first visit, chronological age was 7.6 (1.1) years, and normal height and weight had been attained: height SD score: 0.8 (1.2); weight $+1.5(10.5) \%$. Auxological data of the two groups are presented in table 1 . the two groups: $-0.9(0.4)$ in group 1 and -0.7 (1.3) in group 2. The weight defect was greater, and the body mass index (BMI) significantly smaller, in the girls who were adopted later (group 2): $-7.7(9.8) \% \quad v-13.6(9.1) \%$, and $15.9(1.7) v 13.8$ (1.5), respectively, in group 1 and $2(\mathrm{p}<0.05)$. Age at onset of puberty was similar in the two groups $(6.5(0.8) v 7.2(1.1)$
At adoption, height SD score was similar in 
Table 1 Growth data at adoption and at presentation

\begin{tabular}{|c|c|c|c|c|c|c|c|c|c|c|}
\hline Time of measurement & $\begin{array}{l}\text { Age } \\
\text { (years) }\end{array}$ & Height $(\mathrm{cm})$ & $\begin{array}{l}\text { Height } \\
\text { SD score }\end{array}$ & $\begin{array}{l}\text { Bone age } \\
\text { (years) }\end{array}$ & $\begin{array}{l}\text { Height } S D \\
\text { score for } \\
\text { bone age }\end{array}$ & $\begin{array}{l}\text { Weight } \\
\text { (kg) }\end{array}$ & $\begin{array}{l}\text { Weight deficit } \\
(\%)\end{array}$ & $B M I$ & $\begin{array}{l}\text { B2 onset } \\
\text { (years) }\end{array}$ & $\begin{array}{l}\text { Predicted } \\
\text { height }(\mathrm{cm})\end{array}$ \\
\hline $\begin{array}{c}\text { 1st group }<4 \text { years at } \\
\text { adoption }(n=10)\end{array}$ & $2.4(1.2)$ & $85.2(7.0)$ & $-0.9(0.4)$ & & & $10.9(1.5)$ & $-7.7(9.8)^{\star}$ & $15.9(1.7) \dagger$ & & \\
\hline 1 st group at 1 st visit $(n=10)$ & $7.5(1.0)$ & $130.0(6.8) \dagger$ & $1.4(1.2) \dagger$ & $10.8(1.0) \dagger$ & $-1.9(0.9)$ & $27.6(6.5)$ & $1.8(12.7)$ & $16.3(2.4)$ & $6.5(0.8)$ & $149.8(7.7)$ \\
\hline $\begin{array}{l}2 \text { nd group }>5 \text { years at } \\
\text { adoption }(n=9)\end{array}$ & $6.6(0.9)$ & $113.7(7.0)$ & $-0.7(1.3)$ & & & $14.4(4.0)$ & $-13.6(9.1)^{\star}$ & $13.8(1.5)^{\star}$ & & \\
\hline 2 nd group at 1 st visit $(n=9)$ & $7.7(1.2)$ & $125.5(8.7)$ & $0.1(0.8)$ & $7.8(1.5)$ & $-0.6(1.0)$ & $17.8(2.4)$ & $1.1(8.2)$ & $16.1(1.5)$ & $7.2(1.1)$ & $155.7(6.6)$ \\
\hline
\end{tabular}

Values are means (SD). B2 = breast development.

${ }^{\star} \mathrm{p}<0.05$, weight defect and BMI at adoption $v$ weight defect and BMI at 1 st visit; $\nmid \mathrm{p}<0.05$ : height, height SD score, bone age at 1 st visit of group $1 v$ group 2 ; $\mathrm{BMI}$ at adoption of group $1 v$ group 2 .

years), the second group starting breast development only 0.36 years after adoption.

At presentation, height was significantly greater in group $1(130(6.8) \mathrm{cm} v 125.5$ (8.7) $\mathrm{cm}, \mathrm{p}<0.05$; height SD score: 1.4 (1.2) $v 0.1$ (0.8), p < 0.05), and weight had normalised in both groups. BMI of both groups was similar, having increased significantly in group 2 from the value at adoption. Bone age was significantly more advanced in group 1 (10.8 (1.0) $v$ 7.8 (1.5) years, $\mathrm{p}<0.05)$; in these children height prediction tended to be less (149.8 (7.7) $v 155.7(6.6) \mathrm{cm})$.

In the treated girls in group $1(\mathrm{n}=7$, initial height prediction $146.6(5.8) \mathrm{cm})$, skeletal maturation slowed down during the first and/or second year of treatment, with an improvement in predicted height $(150.4(6.4) \mathrm{cm})$. The five treated girls in group 2 presented at diagnosis with normal bone age (bone age minus chronological age: $+1.0(0.9)$ years) and normal predicted height $(154.8(9.1) \mathrm{cm})$, but during the first years of treatment skeletal maturation advanced rapidly (bone age minus chronological age: $+2.2(0.6)$ years), reducing predicted height slightly $(153.7(6.2) \mathrm{cm})$. During the third year of treatment, bone age maturation slowed (bone age minus chronological age: +1.3 (1.0) years), with a consequent improvement in predicted height (156.6 $(6.7) \mathrm{cm})$.

Six of the treated girls from both groups stopped treatment at a mean age of $11.2(0.8)$ years, attaining a final height which was on average $-0.8(2.6) \mathrm{cm}$ below initial predicted height (final height $152.0(7.0) \mathrm{cm} v$ predicted height $152.8(7.6) \mathrm{cm}$ ). In five girls from both groups in whom treatment was not undertaken because of a good initial predicted height, accelerated skeletal maturation after diagnosis decreased their height growth potential, and their final height was on average $4.1(3.2) \mathrm{cm}$ below their initial predicted height (final height $154.3(4.3) \mathrm{cm} v$ predicted height 158.5 (2.6) $\mathrm{cm})$.

\section{Discussion}

In the industrial world precocious puberty is not unusual in girls adopted from developing countries, and in Belgium these girls account for one third of all cases of precocious puberty. ${ }^{6}$ This phenomenon has also been described in Swedish reports, ${ }^{2}$ and is increasing in Italy. In recent years, 30 adopted girls have been referred to our clinic. Analysis of the 19 girls described here, in all of whom we had full follow up data, shows that those adopted at a later age ( $>5$ years) had a greater weight deficit and a greater delay in bone age than the children who were adopted earlier $(<4$ years of age), while height at adoption was less affected. Bone maturation in these girls shows very rapid progression and puberty is completed faster, compromising final height and aggravating the psychological problems associated with adoption. This is also true, but to a lesser extent, in girls adopted at a younger age ( $<4$ years).

Several hypotheses have been put forward to explain this early onset of puberty. In normal female puberty, an increment in adipose tissue $(+120 \%)$ and in lean mass $(+45 \%)$ occurs. Studies on fat cells in vitro show that there is conversion of adrenal androgens to oestrogens. ${ }^{7}$ Therefore, the rapid increase in body weight observed in our patients is probably associated with an increase in circulating levels of free active steroids which could prime the hypothalamic centres and cause precocious stimulation of the hypothalamicpituitary-gonadal axis.

The original diets of our patients could also be important. Before adoption these girls were mostly on a low protein, low energy, vegetarian diet, which changed to a balanced enriched diet after adoption. Different pathophysiological mechanisms could be involved. Improved nutritional conditions increase insulin-like growth factor 1, which would stimulate both the maturation of ovarian follicles and their oestrogen production, and also the hypothalamic secretion of gonadotrophin releasing hormone, favouring sexual maturation. ${ }^{8}$ Furthermore, in animals food restriction results in increased gene expression of neuropeptide Y. In the hypothalamus this peptide inhibits the release of gonadotrophin releasing hormone. Refeeding increases insulin production, which in turn inhibits neuropeptide $\mathrm{Y}$ secretion, reducing the inhibitory action on the secretion of gonadotrophin releasing hormone, ${ }^{9}$ and favouring the onset of puberty.

Ethnic factors must also be taken into account, especially in the Indian girls. In India, age at menarche in upper class girls is quite low, ranging from 11.2 to 12.8 years, and in particular the mean height and weight are lower at the onset of puberty than in children from developed countries $(137 v 142 \mathrm{~cm}$, and $27 v 33 \mathrm{~kg}) .^{10}{ }^{11}$ Therefore the mean weight of our patients, in particular of the children in group $1(25.5 \mathrm{~kg})$, was very close to the critical weight reported for Indian girls at onset of puberty. 
Psychological factors could also be involved with the triggering of puberty. One of our patients was neglected and abused by her first adoptive family. Puberty began shortly after she was readopted at the age of 6 , and in this new family she found personal equilibrium and serenity.

\section{CONCLUSIONS}

Careful surveillance of girls adopted from developing countries is necessary, especially if they are adopted at the critical age of 4-9 years. Gonadotrophin inhibitory treatment, which reduces and hopefully blocks bone maturation, is indicated when the initial height prediction is low or when it worsens rapidly and progressively during the initial follow up. The suboptimal final heights reached by some of our patients can be ascribed either to the late start of treatment in patients who were already well into their pubertal growth spurt, or to early interruption of treatment. Compliance with treatment and suppression of luteinising hormone were good in all patients and cannot account for the results observed. Treatment should be continued during the early adolescent years because the initial catch up growth and the precocious pubertal growth spurt make it improbable that there will be consistent residual growth after treatment is stopped.

Finally, it is important to point out that some of these girls were referred when they had already attained, or were very close to, their final height. This occurred because of the erroneous belief (unfortunately shared by adoptive agencies, missionaries, and some general physi- cians) that precocious puberty is a normal event in children coming from developing countries. In some of these girls, the inadequate final height worsens the existing psychological problems caused by adoption, the change in culture, different racial and physical features, and other problems in children who often are not very well integrated into their new environment.

1 Winik M, Meyer KK, Harris RC. Malnutrition and environmental enrichment by early adoption. Science environmental en

2 Proos LA, Hofvander Y, Tuvemo T. Menarcheal age and growth pattern of Indian girls adopted in Sweden. Acta Paediatr Scand 1991;80:852-8.

3 Greulich WW, Pyle SI. Radiographic atlas of skeletal development of the hand and wrist. Stanford: Stanford University Press, 1959.

4 Bayley N, Pinneau SR. Tables for predicting adult height from skeletal age: revised for use with the Greulich-Pyle hand standard. 7 Pediatr 1952;40:423-41.

5 Bar A, Linder B, Sobel EH, et al. Bayley-Pinneau method of height prediction in girls with central precocious puberty: correlation with adult height. F Pediatr 1995;126:955-8.

6 Bourguignon JP, Gerard A, Alvarez Gonzales L, et al. Effects of changes in nutritional conditions on timing of puberty: clinical evidence from adopted children and experimental studies in the male rat. Horm Res 1992;37(S1):97-105. $7 \begin{aligned} & \text { Nimrod AK, Ryan J. Aromatisation of androgens by human } \\ & \text { abdominal and breast fat tissue. } f \text { Clin Endocrinol Metab }\end{aligned}$ 1975;40:367-72.

8 Adashi EY, Resnik CE, D'Ercole AJ, et al. Insulin-like growth factors as intraovarian regulators of granulosa cell growth and function. Endocr Rev 1985;6:400-20.

9 Pierroz DD, Gruaz NM, d'Alleves V, et al. Chronic administration of neuropeptide $\mathrm{Y}$ into the lateral ventricle starting at 30 days of life delays sexual maturation in the female rat. Neuroendocrinology 1995;61:293-300.

10 Qamra SR, Metha S, Deodar SD. A mixed-longitudinal study on pattern of pubertal growth: relationship to socioeconomic status and caloric intake. Indian Pediatr 1991;28:147-56.

11 Frisch RE. Weight at menarche. Similarity for wellnourished and undernourished girls at differing ages, and evidence for historical constancy. Pediatrics 1972;50:44550 . 